\title{
MISSION EDUCATION AND \\ NATIONAL POLICY
}

By Professor PaUl MONROE, Ph.D., LL.D.

During the past two hundred years two great political forces have been operative in society, that of democracy and that of nationality. The strongest and the most nearly universal of the two has been nationality. During the earlier part of the period the factors that were thought to produce or to foster nationality were racial homogeneity, religious unity and a common language. Other conditions were also deemed essential, such as geographical unity, a centralized government and similar factors. However, with the growth of democratic ideas and practices it became obvious that, though important, these factors were not the sole or even the essential elements of nationality. The development of the American nation particularly demonstrated that strong nationality might be compatible with or even dependent upon freedom in religious thought and practices and upon the obliteration of racial lines through complete freedom of immigration.

Not only in America but more especially in Europe it came to be recognized that some factor, more inclusive than language, religion or race, formed the basis of effective nationality. This more fundamental basis was recognized as a common culture. By this term is meant not the English idea of culture-an intellectual attainment plus an æsthetic appreciation-but a community of ideas, purposes, traditions, institutions accurately indicated by the German word Kultur. In fact the Teutonic peoples during the eighteenth century were the first to become 2 I 
conscious of the political significance of Kultur. Moreover, they made an additional discovery: namely, that this common culture, unlike race, is an artificial product. It can be manufactured. The process of manufacture is education; not education in the traditional English sense - the attainment of individual culture-but education as a process controlled by the state for political ends. Hence came the development of national systems of education, first of all by the various Teutonic peoples, then by the other European nations, then by the United States; last of all advanced nations, by the English. In fact only in our own generation have either the people of the United States or those of England come to consider education as a national process which is to produce the common culture essential to a strong nationality. Even yet the more popular view conceives education as a matter of individual interest, based on individual effort and aiming at individual culture. On the other hand nearly all other nations, including, be it noted, many if not most peoples toward whom missionary efforts are directed, conceive of education as a group process, legitimately to be controlled by the government for the production of a common culture. To this political conception of education both the American and the English government and peoples are now committed. It is in this sense that education will hereafter be considered in this article.

Education in this group sense conforms to certain laws or principles which are operative in a greater or less degree in all countries; more effectively, perhaps, in countries to which mission education is directed than in the English speaking countries from which missions come. Mission education, it is true, aims at objects beyond those involved in the national or cultural education; it has distinct motives of evangelization and ideals of the development of Christian character in its students. With these distinct aims this article does not deal. But to be successful it must conform to the more fundamental social principles which control education 
as conceived and carried on by the people for whom it exists.

More specifically the writer would argue that to be effective permanently, mission education must so affect the principles and the organization of the group cultural education as conceived by the non-Christian peoples that the ideals aimed at by the missions may to some extent be included in these principles and this organization. This may be done in two ways; first, by modifying the ideals, spirit and purpose of the dominant state education; second, by operating educational experiments which will force the dominant system to imitate the higher type. The most direct way to accomplish the first of these objects is to contribute directly to the state system, wherever possible, through the training of teachers.

The second thesis which the writer urges, based upon the above analysis, is that mission education in the near future is apt to be much less influential than at present, because of the failure to take into consideration the two suggestions made. In the first place the mission schools have paid so little attention to the training of teachers that in many regions they cannot staff their own schools and in few or none can they make any contribution to the teaching staff of the government schools. In the second place the missionary bodies are attempting so much in the way of education, and are wasting so much through competition, overlapping and lack of co-ordination, that however strong some of these institutions now are they will shortly be so outdistanced by government institutions that they will lose relatively much of the influence they now have. Moreover, within the present or the next generation, native institutions will be so developed and so strongly intrenched that the mission education can exert little influence on the government system. When that time arrives the best students will turn to government schools and the missions will have lost their great opportunity. It is true that there will yet remain, perhaps will always 
remain, the opportunity to accomplish much good through the education of a relatively few individuals, and through assistance to the local program of evangelization; but the larger opportunity will have been missed.

However, missions operate under such diverse circumstances and among peoples of such different stages of culture that a further analysis is necessary before attempting concrete application.

In the process of developing a common culture as a basis for nationality three distinct stages may be noted, in each of which missions are now operating. In the first, people are still living in tribal form, under genetic rather than political institutions. Political organization in these cases is now almost universally provided through colonial control.

In the second stage, the peoples are in a transitional state of political organization and are consciously seeking to replace the indigenous culture with the artificial modern product of a common culture. Some of these people, as the Chinese, may have a high degree of native culture, may indeed be more highly 'cultured' than western peoples, but that culture is inadequate to the demands of the modern world. Such people have become conscious of the importance of a common culture, of the kind which may be manufactured by the direct processes of education, and are seeking to replace the indigenous form by the modern product.

In the third stage, the people, having become fully self-conscious of this process, have succeeded in perfecting the machinery for replacing the old culture with the modern one through an effective school system.

In each of these stages the cultural system and the educational process conform to distinctive principles or laws peculiar to the given stage. It is a further argument of the writer that mission education should conform to these conditions. In other words, it is argued that the mission education policy for people in the first stage should 
be very different from that in the second and the third; that in the second or third it should differ from that in each of the others. This argument may be supported by the following application.

\section{II}

The first stage, that of primitive cultures, is illustrated by the various African peoples, the non-Christian peoples of the Philippines and of the East Indies, and no doubt by other groups. With such peoples the fundamental need is not for a literary education, but for one which will include all the essential elements of modern civilization and Christian culture. Education along economic lines should give them modern methods in industry and in agriculture, which will enable them to become self-supporting in a new environment, to contribute to the world channels of trade and to avoid exploitation by Christian nations. For such peoples the missions should lay great stress upon trade or industrial schools and upon agricultural schools. An education which is merely literary is apt to result in the separation of its beneficiaries from the masses of the people, in the creation of an intellectual caste which in time leads to an exploitation of the masses by their own leaders little less reprehensible than exploitation by outsiders. Such peoples need an education in personal hygiene and in public health which will enable them to withstand the evils introduced by commerce and by new conditions of living; this may be necessary to prevent complete extermination such as has actually occurred in the case of some peoples of the Pacific islands among whom missions operated early in the nineteenth century. Such peoples need a moral education which will enable them to withstand the contact with the morals-or the mores-as well as the immoralities of Christian civilization. They need an intellectual education also, but one associated not so much with books and linguistics as with the simple practical 
processes of the life which they must lead. All the educational elements mentioned can be blended in such practical schools and all, including the intellectual, will be far more effective than if isolated in a modern academic procedure. What is needed is the education of a Hampton or Tuskegee, not that of a New England college or high school. The methods of the latter would benefit a few individuals, but for the most part would entirely eliminate them from their native environment or would nullify their native influence. Religious leaders these people need and such leaders must be produced and trained; but their influence would be exerted more effectively through the religious aspects of occupation, family life, social customs, than through philosophical and theological effort. Their native religion is intimately connected with their industries, their home and tribal customs, and every act and thought of daily life ; the higher religion which replaces the genetic one should be no less intimately connected with all these.

\section{III}

With the second stage of this cultural development the problem grows more difficult; in fact it presents the greatest difficulties of the three, both because it is most complex and because it is fraught with the greatest possibilities and promise. Here would be included China, India of the past and the Near East, the great mission fields of the world. Such peoples possess cultures far older than our own, almost as complex, just as stable, perhaps even more so, and in many essential respects just as high. But with the exception of the Near East population, these cultures do not include Christian ideals. And, reverting to our main thesis, such peoples are not yet conscious, or are just becoming conscious, of the significance of a common culture as a basis of group unity and of group progress. They are becoming conscious also of the significance of a controlled educational process as a means to this national unity and 
progress-far more conscious of it than are the mission educators who work among them. Therein lies one serious aspect of the present situation.

Let us try to analyze the educational problem at this stage. From our point of view these people need all the elements of a Christian culture. From their own point of view they need an education which will give them all the essential elements of complex modern culture. It is not possible to give them only a religious education and expect that to stand. It is not possible to give them an intellectual education only and expect that to function. We do not undertake at home to convert an individual to the Christian life and attempt to influence only his religious thought and feeling. We expect his religion to affect his conduct in vocation, in family life, in politics, in social relations. It is true that it does sometimes happen that a man is converted only as to his religious life, the change not visibly affecting his business practices and his other relations. But we are not so proud of the result as to seek to reproduce it elsewhere. And with us the individual so "educated' has the advantage of working in institutions and following customs that are substantially controlled by Christian ideals. The convert in a non-Christian land has not this benefit. Hence the necessity of seeking to modify every phase of culture, of developing every phase of a Christian community, of training leaders in every phase of social life, in industry, in commerce, in politics and the professions; of developing the laity as well as religious leaders, and of attempting to establish on the basis of Christian principles all the essential aspects of modern culture. An attempt to give a religious education which is inhospitable to modern scientific ideas, or which is not accompanied by a training in modern science, will defeat its own ends. A mission education that does not make provision for the training of future political and social leaders will eventually find itself situated in a society of modern structure with governors hostile to the education 
which neglected this essential feature. When the third stage of development is reached, as may soon be in all these countries, such political leaders will have both power and means for the realization of their hostile purpose.

Let us confine our discussion for the moment to one country, China. The education which China needs, and of her own volition is now seeking, includes all the elements of modern culture, industrial, economic, hygienic, medical, scientific, political, social, professional, religious. Mission education must offer no less, or at least must offer the preparation for no less. The root of the difficulty is that mission education was formulated when in essential aspects China was in the early stages of the second culture period. Perhaps even yet the basal organization of Chinese society is the genetic one of family or clan rather than political. Therein lies the political problem of that people. A further difficulty is the enormousness of the problem. It had to be attacked piecemeal; efforts had to be confined to small groups, to isolated localities. To this day the need as well as the opportunity is so great and the results so significant that it is difficult to consent to sacrifice isolated efforts in favour of a larger plan which contemplates the future as well as the present.

The magnitude of the problem is such that a definite and rational policy should be adopted. It is so huge that no agency save that of the conscious organization of the entire group, that is the nation, can accomplish it. Hence the missions must seek for some other aim than the education of the masses ; that is, of all of the people even in any one community. Only an organized Chinese people, acting through their own government, can do that. And, when so organized, the nation will do it irrespective of what mission education may desire. Nor can missions look forward to educating all the leaders or even attempting to do so ; that possibility is passed even now. One native institution, the national university, has now nearly 2500 students, of university or at least higher grade, pursuing 
western science. It has a budget of nearly a million dollars and has on its staff of three hundred some distinguished world scholars. Practically a part of the same institution is the higher normal school, with eight hundred additional students, a half million additional budget. The combined institutions have a staff of over 400 , nearly a fourth of whom are returned from foreign training. Probably all the mission institutions of higher grade combined cannot equal this one in budget, student body, staff or number of returned students employed. The government plans four such institutions ; the missions have two or three times this number aspiring to be colleges or universities. Mission education must seek some other aim than this.

Can such an aim legitimately be found in the support of a considerable number of institutions of higher learning, including professional schools? The budget submitted for one such agricultural school as planned for the future totals $\$ 100,000$. Many such at home cost much more. Engineering schools demand even a more generous support; the Peking Union Medical College has a budget of $\$ 800,000$, which is about the expense of a similar institution at home. Though this school cannot hope to train one one-thousandth of the physicians which China will need, the China Medical Board has withdrawn other contemplated schools of a similar character as beyond its ability to support. Can the missions contemplate more? The task of training all the professional experts which China will ultimately need and will soon demand is one impossible for private resources. When the Chinese people come into full selfconsciousness and political self-control, it is certain that they will not permit the training of the bulk of the nation's professional experts at any time by private authorities, even were this feasible.

What then should be done? As one policy it is possible to develop a considerable number of agricultural, medical and other professional schools or colleges of moderate proportions, meeting needs that are urgent with the expec- 
tation that they will soon be outclassed by government institutions. Then the outclassed mission schools either can be abandoned or turned over to the control and support of the native Church or of private authorities. As a second policy these schools may be allowed to vegetate as second-rate institutions or less, to be viewed with indifference by the Chinese. A western institution inferior to a native one has little prestige in the Orient. A third, and it would seem a better, plan would be to limit higher educational activities to a very few institutions, attempting professional work in any one line in only one or two institutions. The purpose would then become to make the work in any one line so excellent and so effective that it would serve as a model for similar work undertaken by government authorities, and to train efficient leaders for these professions rather than the rank and file. The mission forces now probably have at their command the educational resources to do this better than the government can, and have also the moral force which the government lacks. The adoption of this plan would mean the cessation of competition among a large number of institutions inadequately supported and equipped and the elimination of overlapping. It would mean also a close adjustment of mission education to its Chinese environment.

One of the two chief objections made by the graduates of mission schools who have come into wider contact with western education is that their training failed to give them any close contacts with the actual conditions of Chinese life; the object of the missions seems to have been to establish replicas of New England colleges or of English public schools without any sufficient consideration of their relation to the Chinese environment, including native religious and moral ideals. The force of such criticism is now assuming serious proportions. The most feasible way of obviating this criticism through academic channels is through motivation of the scholastic work through direct relation to the needs of Chinese society. When such 
motivation is called vocational or pre-vocational or industrial or professional, it is apt to arouse the antagonism of many mission educators. Some reflection and inquiry, however, will reveal the fact that the chief difficulty with American collegiate education is the same, namely, that it lacks adequate motivation. Intellectual curiosity, desire for learning as such, or the research motive may be sufficient for the instructor; it is seldom sufficient for the student. He needs and demands a more concrete and a more immediately realizable end. The search for such motivation is the chief characteristic of present conditions in higher education in America. The most obvious solution is the beginning of professional work at the end of the junior college, as is done in practically all state universities and in most of the great endowed universities. The chief reason it is not done in the smaller institutions is the prohibitive expense of administration. Probably the majority of American college students are so grouped in professional or pre-professional courses. There is no reason why such a policy should not be followed in the mission schools of China. This would coincide with the government educational projects, with tendencies in America, with practices long existing in Europe, and with modern educational thought.

One notable exception should be made to this generalization, and this for two reasons. In the training of leaders in religious life, in politics or in law, an intellectual education should be given as rich and as prolonged as the economic condition of society makes possible. For in all the countries in this second stage of culture development, which is practically all of the Orient, learning is in high repute for its own sake. The learned man, the teacher, the student is held in higher esteem there than in any country of the Occident. Western culture if it is to replace the oriental must be represented by learned men, by intellectual leaders who are the peers of the intellectual leaders of the old culture. Hence the leaders in Christian thought, 
in religious life, in civic and public life must receive the widest possible intellectual training. The second reason is that the subject matter of the senior college course is usually that necessary for training in these professions. In its origin, and for long thereafter, the American college furnished the professional training for these two careers of church and state. Even yet the general materials included in the law course in continental European countries and in Latin America is usually presupposed in American law schools and hence incorporated in the college curriculum. In other words the senior college really becomes a professional or pre-professional course for the minister and for political and legal leaders.

Secondary education presents a somewhat similar problem though one of greater extent. The secondary school aims primarily at the selection and training of the leaders. Particularly is this true if this secondary school follows European tradition and includes the training of the pupil from the eleventh or twelfth years of age to the eighteenth or nineteenth. To accomplish this end the period may be divided into two schools, to conform to government standards, though it will doubtless ultimately seem to be most advantageous to organize the period into one school unit of from six to eight years in length.

The social function of secondary schools is to select pupils of the necessary ability to continue into the professional schools, and in a larger way to prepare the rank and file of leadership in all lines. The opportunity and need are so great and the task for China is so huge that it is a legitimate aim, and one promising adequate returns for the missions, to enter the secondary school field to the extent that the work can be well done without limiting other policies. However, it is far better to do a limited amount well than a larger amount poorly; better, that is, for the ultimate attainment of the aims of mission education. It is true also that much of this should frankly be vocational or pre-vocational, for the reason advanced above. 
The scheme of organization should synchronize with that of the government in order that the secondary and higher mission schools may be able to draw largely from the government elementary and secondary schools, while the government higher schools under certain conditions may draw from the mission secondary schools. The facilitation of these interchanges will advance the great purpose of mission education, namely, to exert a Christian influence in moulding the character of the native leaders of the coming generation.

As to elementary education perhaps but one additional consideration enters the argument. For the present the need is so great that every effort is worth while; elementary schools are needed as feeders to the higher schools; they are needed as models for government or native schools. The additional consideration is that mission elementary schools will be needed for the nurture of the Christian community, until the government or other native schools are so permeated with Christian spirit and purpose that the children of the Christian community may with safety be left to them. As the ultimate aim is to bring about this transformation in Chinese society, it may be said that the test of the success of mission education is the extent to which it may eliminate itself.

There is one other fact which to the writer seems the most important of all. If the immediate object of mission education is to bring Christian influences, ideals and purposes to bear on the Chinese youth, there would seem to be no more effective way of doing this on a large scale than by shaping the character of those who are to teach and control the government schools. By such means mission influence on one Chinese boy or girl may be multiplied a thousand-fold, and be exerted by and exemplified in those through whom China must be Christianized, if ever-namely, by the Chinese themselves. Yet comparatively little is being done in this respect and that little of very recent origin. Some years ago the writer visited a 
considerable number of mission centres and found in all of them efficient schools, many of them with fine plants. In some centres there were several such plants. In only three or four of these centres was any effort being made towards the training of teachers and that in a most desultory way. He recalls no such class that had more than a score of pupils. Yet in each one of these centres government normal schools for both men and women were visited, having an attendance of from two hundred to a thousand each. All of these students were taught after the Japanese method and in the Japanese spirit. Yet in these same regions the government officials were willing to use all the teachers that the mission schools could furnish. It seems lamentable that so great an opportunity was missed and is still being missed.

The responsibility for this situation lies not wholly on the shoulders of mission administration. It is but a part of English and American tradition. In no progressive country in the world, including China, Japan, Latin America and most countries of Europe, is so little emphasis placed on the training of teachers. The reason for this condition is simple. Education has been conceived of as a local not a national function. Its purpose has not been to develop a social culture upon which a strong bureaucratic or even autocratic government could be built. Democratic, not nationalistic ideals have controlled. Initiative, self-dependence, ' self-activity,' self-control, have been aimed at in the pupil ; the same characteristics have been deemed quite sufficient for the teachers. Hence an elaborate technical training supervised and provided by the government has not been deemed essential. This situation is now generally admitted to be quite inadequate. And it is a serious error for western educators to repeat the mistake where higher standards are set up.

It is even a greater mistake to send over untrained teachers to serve as models in competition with trained teachers. The very fact that the mission teacher comes as 
a representative of a superior education sets him up as a model. It may be freely admitted that the mission educator has a vast advantage in the knowledge of the subject matter to be imparted, in personal culture and in force of personality; but a knowledge of technique is often quite as important. At least it gives its possessor the feeling that it is. All the government teachers have had from one to four years of technical training, many of them in Japan, some few abroad. To see the American college graduate blundering through the process of teaching the elements of his native language, because he has had no training in the technique, and is probably even unconscious that such training exists, and to compare his work with that of his Chinese neighbour who is engaged in a similar process, and who has had two or more years' training in technique, though it may have been mechanical, brings no credit to the former.

Professional study is desirable even aside from technique. Suppose an argument arises whether secondary education should include professional or vocational courses. The untrained teacher probably would not know, though his Chinese educational acquaintance might, that at least forty per cent of the two million pupils in the secondary schools of the United States are majoring in vocational lines; that twenty-eight per cent of the total are in the one field of commercial education. Suppose the argument was that the mission schools should follow the American plan and have an eight year elementary course instead of a five or six. He probably would not know, as his professionally trained friend might, that 500,000 American children are now in junior high schools instead of the old seventh or eighth grades. Perhaps the question in dispute is whether academic collegiate training should extend the non-professional work of the student through a period of sixteen years or whether the senior college should offer professional and pre-professional courses. The American college graduate's experience would probably not acquaint 
him with the fact that with few exceptions all American universities allow and provide for this plan and that most professional students adopt it.

The point of the argument is that American mission educators need a professional training before they are sent out as truly as do medical or religious workers. To omit this is not fair to them, to their constituency, or to those among whom they work. Further, it is urged that larger provision should be made for the higher training of native teachers in mission normal schools and that normal courses should be established in numerous secondary schools as well as in colleges. The Philippine experience shows that a fairly effective teacher training can be given even in the intermediate school. This, however, was in a less complex society and was an expedient to furnish quickly the large number of teachers required for a government system.

Throughout the whole educational programme there should be sought as an objective a close contact with Chinese life, an approximation to the spirit of the Chinese or to their thought life, an attempt to carry over as much of their old culture as is compatible with the new. In some respects the mission schools may be doing this. But the failure to preserve the contact with Chinese life and thought results in an exotic religion and culture and detracts from the realization of the primary aim of mission work-the Christianization of China. This being the first of the criticisms offered by the products of mission schools, the second one may be properly mentioned here-namely, that too little use is made of the product of mission work and of the natives in general in the operation, control and direction of mission work, educational and otherwise. The failure to do this now does of course delay the realization of the ultimate purpose of turning all work over to the native Christian Church. The point of the argument is that it should be done progressively and as rapidly as possible. Whether the second criticism is just or not the writer cannot state, but he is able to affirm that it is one frequently made. 
To summarize the significance of the second stage of social development and mission work, it may be pointed out that its chief characteristic is the vague recognition by the people of the importance of education as a means of developing a common culture which will serve as a basis for nationality, without their having as yet developed the power to control the process.

The classic example is in the Balkans. Here Greek schools, Bulgarian schools, Serbian schools, Turkish schools, even Armenian schools, Italian schools, American, British and French schools have competed to this end. All of them are looked upon by the natives and by the local governments as direct proselyting agencies for their respective peoples. A partial exception may be made in the case of the British and American schools. With the same exceptions it may be frankly admitted that the schools are such agencies. Political allegiance follows the religions; schools determine the religion of their pupils and indicate that of their parents. In both the fact and the common recognition of the fact by the natives lies the necessity of a mission policy which should meet this condition.

All the peoples of this second group are making great effort to acquire such self-control-a political and cultural control through schools. The chief problem for mission education is to formulate and adopt such a policy as will preserve their influence, as will allow it to make the maximum contribution now and to retain its influence on ideals and purpose, as will permit it to offer models and to continue to contribute effectively to leadership when the culture development shall pass into the third stage.

\section{IV}

The third stage of cultural development is reached when the group attains complete self-consciousness, sets up definite group aims, and constructs and supports an efficient political government which adopts definite pro- 
cedures for realizing these ends. The most fundamental of these group aims is that of creating, maintaining and developing a common culture. The most significant of the procedures for realizing these ends, and the only one adequate to secure a common culture, is a nationally controlled system of education.

Mission education in such countries confronts a quite different problem from that found in the earlier stages. Mission work in Europe, in Latin America and in Japan would fall into this group. Here it is obvious that there may be two distinct situations, one in which the dominant government and the peoples are Christian, the other in which they are non-Christian. But the political and social principles underlying educational work would be largely the same in the two cases. Mission work and mission education in the Christian lands would obviously have a much more restricted object and a narrower justification. Into the question of the ethical and religious principles involved here, this article will not enter. To arrive at the social and political principles involved, it will suffice to consider the one outstanding non-Christian nation of this group, namely, Japan.

The outstanding fact that mission education must face in its work with all peoples of this third group is that such people have determined to use education as a means to a national end and that they may consequently compel nongovernmental education to conform to many of the fundamental requirements of state education. Their political, social and even ethical right to do this cannot be gainsaid. These requirements relate usually to the qualifications of the teacher, to the subjects taught, to the relative number of nationals and non-nationals in the administrative and teaching staff, to the actual administration of the school and to the teaching of religion.

It is the application of some or of all these requirements that has caused the curtailment of mission education in Japan and has restricted its influence. It is a similar 
situation that is causing so much trouble in Korea at present and that promises difficulty in China, India and the Near East, in the future. Since the enforcement of such requirements is often objected to by the mission educator, by his supporters and by his administrative superiors, and since this situation promises to be a most serious problem in the future, let us examine its premises briefly before discussing an advisable policy.

The requirement which caused most curtailment of mission work in Japan was that the teachers should have a given number of years of professional training. All teachers in the elementary schools of Japan must have had four years of normal school work, and all in secondary schools must also have had secondary school education preliminary to the professional. All schools possessing rights similar to government schools must have on their staff a certain proportion of teachers measuring up to these minimum standards. Mission administrators do not yet have any adequate conception of the importance of the professional training of teachers, so naturally the mission schools were not prepared to fulfil such requirements and suffered accordingly. Not that mission educators and mission administrators were wholly to blame. The American people as a whole have no such standards and have no such belief in the professional training of teachers. The facts available are not entirely comparable but they are these: The Japanese teacher in the elementary school must be a graduate of a normal school which gives him a professional training of four or even five years and is approximately equivalent in length to our secondary school. The teacher of a secondary school must have a professional training of four years which is beyond the secondary school. In the United States less than fifty per cent of our 650,000 public school teachers have the requirement of a full high school education; less than twenty per cent have a high school education plus a two year professional training. The question is, is it advisable to set up an inferior professional 
standard in a foreign country even in the name of missions ; and, if so, is it advantageous to the missions themselves to do so?

Reverting to a previous argument that is pertinent at this point, it is the prospective application of this requirement to non-governmental schools that is apt to furnish the point of contact and of conflict between the government education and missions in China. At present it looks as though the missions would not be prepared and the government will be in the right as to position and principle.

The second requirement which is apt to cause difficulty is that all instruction must be given in the native language. This is now accepted without debate so far as schools in Japan are concerned. The difficulty arises in the colonies or the lands subject to the Japanese, especially Korea, a question discussed in the following paragraph. A more serious aspect of the question will arise when the Chinese government shall establish this rule. Wherever this point has been considered in the United States, legislation has always enunciated the principle that all schools should be taught in the English language. Numerous commonwealths have adopted such requirements. Wherever the question is up, the attitude of the American people is unquestioned, namely that they have a right to make such a requirement for the security of their culture and political institutions. American interests operating in foreign lands are in no position to advocate any other policy.

A third requirement which may cause difficulty is that of certain minimum essentials of the curriculum. The point here lies in the inclusion of elements which are considered essential to the native culture or the exclusion of elements which may be considered essential to the culture of the mission educator. The mission schools naturally find it difficult to teach Japanese history and political theory as they are taught in the government schools. It becomes more difficult to do this in Japanese-controlled Korea. Has the Japanese government the right to demand this and must 
the mission schools conform? When the Japanese government objects to the teaching of the American Revolution and the patriotic services of Washington, or of the American Civil War in the schools of Korea, because of the political influence of such teaching, what answer is to be given?

Before answering authoritatively, one must study the attitude of American governments towards similar questions. Certain American states have recently passed very drastic laws directed towards controlling the economic and political beliefs of teachers. It is hardly to be denied that there has developed or is developing a new orthodoxy. The question of religious orthodoxy no longer interests the masses of the people or the government authorities. But the question of political and economic orthodoxy does. Without discussing the merits of the case here, the one point of concern is perhaps obvious. As believers in democracy we can hardly demand privileges in foreign lands which we are not prepared to grant in our own land. It is not sufficient to answer that as individuals we do not accept this position. As long as our governments exercise such rights, we are in no position to deny them to foreign governments under which we seek to exercise the privilege of educating their youth.

A fourth point concerns the administration of schools. It is probably admitted that as a matter of policy it is best among peoples where the government is entirely competent to have mission schools administered by natives. The problem arises acutely when this becomes a legal requirement. This condition is likely to arise soon, the precedent being set by Christian nations. If we revert to our fundamental thesis, that education is now recognized as the means for determining the culture of a people and that all individuals should participate in such a culture, the validity of such a demand can hardly be questioned.

The fifth problem, which is the most serious of all to mission educators, concerns the teaching of religion. Declaring Shintoism not a religion but a system of political 
and social ethics, the Japanese bar the teaching of religion in the schools. The same attitude may be taken by the Chinese regarding Confucianism. The Japanese government forbids the teaching of religion in mission schools to which the privilege of government schools of the same grade are granted, but has allowed the teaching of religion in these schools if it is not a part of the regular curriculum or during the regular school hours. In doing this they claim to be following American precedent. If we grant that mission schools having the privileges of government schools are in fact government schools, this claim can hardly be denied; for it does not seem to be possible that mission schools can exercise the right of government schools and yet refuse to accept obligations of such schools.

In this position Japan is but acting on the principles followed or at least sanctioned by other governments. This much will be granted. Difficulty and sharp disagreement will arise concerning two other applications of this theory. One difficulty has already arisen. In certain regions, at least, the Japanese government has declared that religious instruction offered after school hours, if given to substantially the same body as constitutes the school population, even though other than school buildings are used for this purpose, is in fact religious instruction in the schools. This is carrying the separation of religion from education further than Americans, whether interested in missions or not, are prepared to sanction, or to consider within the proper scope of government. No American experience can be considered as a precedent; neither law, nor tradition, nor form of government would permit it. What political grounds we might have for combating this decision is another question. Whether the Japanese government will persist in this attitude cannot be said, for the question is still under discussion. Certainly adherence to this view would place mission educational activities under such handicap as to render the accomplishment of their main purpose impossible.

This position of the Japanese government is taken on 
the grounds that religion forms no part of education; that the missionaries are free to engage in religious activities and propaganda as they may wish so long as no law is contravened; but that education is a government function, and that if such function is delegated to non-governmental agencies, such agencies must confine their activities within educational lines. This attitude foreshadows the second point of disagreement, a view which, if adopted, will render mission education almost impossible. Considering the recent rapid development of education as a function of government, for the purpose of determining the basal culture of a people, and thus laying the foundation of the social and political structure, it is quite possible that government should limit the exercise of this function to its own agents. In practice a number of European countries have substantially reached this position. All but a small fraction of the school population in these countries are in government schools, and those that are not are closely supervised. The French government has added to this situation the exclusion of religious teachers from the government teaching staff. The new Mexican constitution makes just this proposition : that none but natives with government authorization can teach. While this is not as yet enforced, it may be. It is towards such a position as this that the governments of the world, particularly those of less developed or smaller peoples, are moving.

It is through no unfriendliness towards or lack of appreciation of missions that this situation is pointed out by the writer. But it certainly is the part of wisdom for mission educators to take cognizance of the tendencies, to keep the conditions in view and to attempt to formulate their policies in accordance with the situation.

\section{V}

To the three types of culture and political organization under which missions operate a fourth must now be added, 
chiefly as a result of the war. This final type includes the so-called mandatories, to which should be added Korea and probably India. The characteristic of this type is the dominance of a people in the first or second stage by one of the third stage, to the end that the culture development of the fostered people shall be assimilated to that of the dominant one. The present world situation indicates that possibly, if not probably, all colonial governments will be transferred to this group. Certainly less freedom is to be allowed to missionary agencies in all such regions than in the pre-war period. The immediate future will reveal whether India is to be transferred to this stage, so far as mission educational activities are concerned, instead of to the third stage. The same problem arises in Egypt, with the indication that shortly the mission problem there will fall into the third stage. In certain fundamental aspects the mission problem in the Philippines under the American government lies in this fourth group. However, here the educational force is so much more under control of democratic than nationalistic ideas that the problem of the relation of missions and government hardly arises. The fundamental democratic principles that nationality should be based upon complete religious freedom, upon the separation of religion and public education, and upon a fusion of social elements and interests rather than upon racial identity, have controlled the educational situation in the Philippines; consequently, notwithstanding the fact that the established government education has required the use of the foreign tongue of the dominant colonial government and has included as minimum requirements essential elements of the dominating culture, yet these have favoured the development of a common native culture. Complete freedom has been allowed to mission education and to native educational endeavour. The only pressure that has been applied is the attractive, rather than the compulsory, force of a superior educational scheme.

Even the brief experience of the last few months indi- 
cates that a much more rigid policy in the control of mission, as well as of all other education, is to be exerted by those governments holding colonial or mandatory power. The experience of several years in Korea indicates the validity of this statement and also shows some of the results of such policy. It cannot be denied that all such governments are likely to exert considerable authority in controlling the culture development of their colonial wards to the end that it may be sympathetic towards the culture of the controlling power and favourable to its economic and political welfare. Despite the announced principles regarding mandatories, requiring that they shall be exercised for the benefit of their wards, it is quite evident that the real effect of this guardianship will be to direct their development for the advantage of the controlling power. Perhaps this may change in the near future. The recent action of the English government in India in relinquishing the control of education to the native provincial governments is the most significant step in this direction yet taken.

There is extreme, and it seems unnecessary, reticence in regard to the present situation, but a few facts may be cited to prove the point. In the Near East, American evangelical institutions of long standing have been compelled to change the language of instruction from English to French ; in some of these the mass of the Roman Catholic Church must be celebrated for the children. Other institutions of high repute, built up by great investment of funds and lives, are being forced to contemplate removal from French mandatory territory to the regions of English mandate. In India the English government has excluded all German missionaries for a period of five years with the promise to reconsider the question at the end of that period. In 1816 it proposed a bill which required all missionary institutions to give a certain proportion of the instruction in English, to include instruction in English history and institutions, and to employ a certain proportion of English nationals on the teaching staff. In institutions of certain 


\section{International Review of Missions}

designated grades, English nationals must be at the head. Later this proposal was withdrawn, but the principles involved were at least considered as tenable.

In Korea the policy has been carried further than in any other region. Here the Japanese government has required that every missionary school shall give instruction in the Japanese language. This requirement placed such a burden on the numerous small mission schools conducted in Korea, through the necessity of employing expensive instruction in the Japanese tongue, that many of them had to be abandoned. Other requirements as to the minimum program of instruction added burdens, towards which mission schools as well as natives were unsympathetic.

Whether acceptable or not it is obvious that such colonial governments are going to exercise powers quite unfavourable to mission educational activities as carried on in the past and that they have the political power and the political right to do so. Before answering the question as to whether they are also morally justified, we should inquire concerning the action of the American state governments in the conduct of education during the past few years.

Numerous states of the American Union have passed laws requiring that all instruction in private as well as public schools shall be in the English language, allowing the use of a foreign tongue only in the study of that language. It is quite obvious that such laws have the approval of the masses of the people. Such legislation has the same object and is based upon the same principles as similar action in these colonial regions; namely, that of shaping the cultural ideals and activities of all the people towards the common end of a national unity. Many communities have gone to the length of forbidding any instruction in the German language in the common schools. Numerous communities exclude instruction in German from the secondary schools as well. This latter is obviously temporary, and an evidence of war psychology. The other laws ante-dated the war but had not been enforced. 
Several states of the Union adopted laws eliminating teachers holding unorthodox views on political and economic questions. Some of these are quite as extreme as those cited above for the control of the character of school teachers. New York proposed inquisitorial laws to the same end that were quite as drastic as any in operation in other lands. The chief difference is this : that in a democratic community the enforcement of such laws is quite impossible in the face of the opposition or even the indifference of the mass of the people; while under an autocratic government, such as any colonial government is apt to be, the operation of such legislation is entirely feasible, even automatic.

Since mission education is face to face with such conditions in numerous regions, it may be well to summarize the essential aspects of the situation. Such mandatory governments are apt to impose fundamental requirements upon all schools, public and private; first among these is that of instruction through an official language, not necessarily the native one and not the one native to the missionaries. Second is the requirement of certain minimum subjects of study, including the language and literature, the history and institutions of the governing power. Third is the requirement of certain qualifications of teachers, particularly as to length and character of professional training; fourth, the national allegiance of the teaching staff and of the administrative head of the school.

Mission education will find it quite difficult to adjust itself to this situation. The third requirement may be expanded into a fifth if it should be made to include designated political and economic beliefs, or a given attitude towards the existing government. If this should be required, as it is by some American state authorities, mission education will find itself in an impossible situation.

To these stipulations may be added a sixth, that no religious instruction may be given in schools of any character. This would be defended on the grounds that all 
education aims to determine the culture of a people; that this culture is essentially a matter of political or national concern; that individual or outside interests may be free to appeal to the religious interests of the people but that they may not do this through any control of educational channels which serve as a substitute for governmental educational agencies. Both Japan and Mexico have clearly indicated an approach to this position.

\section{VI}

In the face of our own policy, American missions cannot justly require a different one of a foreign government. Nor can they properly rely on the power of our own government to force the adoption of a more favourable or lenient policy in a foreign land. Even if success crowned such an effort, it is obvious that mission education or any religious work which must rely on political or military force is stultified and in the end ineffective.

It is obvious that mission education in these lands is facing a serious and a difficult problem. It is also obvious that old policies and ideas and the old attitude of indifference toward the governments under which they work, or toward the culture which they seek to modify, can no longer persist. It is perhaps impossible to forecast the future or to state the lines of policy which missionaries should pursue.

Certain guiding principles, perhaps, may be suggested as tentative proposals; merely tentative, since it appears that the general political situation of the immediate future is quite a new one.

Recognition of a government authority and the right of a superior government policy with regard to the components of a group-culture, and means for securing this, must be recognized. Mission education should adapt itself to the government education so far as this is not incompatible with its essential religious aims. It should seek to cooperate with and to contribute to this government policy so 
far as possible. It should hold fast, however, to the fundamental purpose of aiding the people for whom it labours. To this end missions must seek as rapidly as possible to throw the control, direction, and support of education and religious training upon the natives themselves. They should recognize that their influence on the educational policy of the government will probably be limited to the indirect pressure which can be exerted through the maintenance of superior or model educational enterprises, and through shaping the character of native or government leaders and teachers. To this end they should endeavour to educate leaders through their secondary and higher schools and to train teachers through their normal schools. It should be recognized that their present contribution to the latter end is woefully inadequate.

This article is written with keen appreciation of the result of mission education in the past and the present, and in the hope that its ultimate aims may be realized in the future. It is written also under the assumption that these ultimate aims do not include the perpetuation of our denominational organization and sectarian differences among people for whom such differences can have little of the historical justification which they may have with us; but under the assumption that the fundamental desire is to establish a native Christian Church which may assume as speedily as possible the entire task of Christianizing the culture of the whole people, and that these ends are to be secured through the Christianization of as many as possible of the individual participants of that culture. The writer also assumes that such peoples are entitled to make their own interpretation of Christianity in the light of their own culture, their own modes of thought and their own historic backgrounds. If Japan could assimilate all the essential elements of the material culture of western civilization in one or two generations, this does not seem an impossible task. It would also seem, in the light of Japanese experience, to be wiser to urge and assist such peoples to make their own 
organization and interpretation of Christianity than to insist that they must fit themselves into the peculiar and perhaps temporary moulds of existing western thought and organization.

Mission education, merely as education, even aside from its Christian motivation has much to contribute to these retarded or recently emerged cultures. The fundamental importance of personality, the necessity of individual variation as the basis of progress, the significance of individual initiation in social, political and industrial life, the value and the virtues of democracy, the deadening influence of a mechanical bureaucracy through a letter perfect technique are all to be conserved as of highest importance. But this can only be done by avoidance of some of the obvious shortcomings of democratic education, by breadth and tolerance of view and by the incorporation of some of the acknowledged virtues of the nationalistic conception of education. In these respects the problems of mission education are the problems of education at home.

The function of privately controlled education at home is to point the way to educational advance through its greater freedom of initiative and experimentation. The function of education inspired by the religious motive is to formulate and work out a comprehensive scheme of education which shall include essential elements of culture and personality which are apt to be minimized or neglected in the mass education controlled by the public. The function in mission education is to serve these purposes abroad in much more difficult situations.

Paul Monroe 